\title{
Pretreatment of cotton spinning residues for optimal enzymatic hydrolysis: A case study using green solvents
}

\author{
Douglas H. Fockink a, b, Jürgen Andreaus ${ }^{c}$, Luiz P. Ramos b, *, Rafał M. Łukasik ${ }^{\text {a, ** }}$ \\ a Unidade de Bioenergia, Laboratório Nacional de Energia e Geologia, I.P., Estrada do Paço do Lumiar 22, 1649-038 Lisbon, Portugal \\ ${ }^{\mathrm{b}}$ Research Center in Applied Chemistry (CEPESQ), Department of Chemistry, Federal University of Paraná - UFPR, P. O. Box 19032, Curitiba, PR, 81531-980, \\ Brazil \\ ${ }^{\mathrm{C}}$ Departamento de Química, Universidade Regional de Blumenau, 89030-903 Blumenau, SC, Brazil
}

\section{A R T I C L E I N F O}

\section{Article history:}

Received 9 March 2019

Received in revised form

11 May 2019

Accepted 10 June 2019

Available online 14 June 2019

\section{Keywords:}

Imidazole

Biomass valorization

Crystallinity

Delignification

Cotton residues

\begin{abstract}
A B S T R A C T
The effectiveness of imidazole and ionic liquid pretreatments for the conversion of cotton spinning residues (dirty cotton residue - DCR and cotton filter powder - CFP) into soluble sugars was investigated. DCR was pretreated with imidazole using temperatures and reaction times that were arranged in a $2^{2}$ factorial design and pretreatment performance was evaluated by enzymatic hydrolysis. High glucan to glucose and xylan to xylose yields $(78.0$ and $94.9 \mathrm{~mol} \%$ ) were obtained from the solids produced at $140{ }^{\circ} \mathrm{C}$ and $2 \mathrm{~h}$ (center point), which provided delignification levels of $45.5 \%\left(\mathrm{w} \cdot \mathrm{v}^{-1}\right)$. The same pretreatment condition was applied to CFP yielding only $16.0 \%\left(\mathrm{w} \cdot \mathrm{v}^{-1}\right)$ of delignification, but $75.8 \mathrm{~mol} \%$ of glucan and $95.7 \mathrm{~mol} \%$ of xylan were converted as their corresponding monomeric sugars after enzymatic hydrolysis. Both pretreated materials were subjected to a central composite design to find the best enzymatic hydrolysis conditions regarding substrate total solids (TS) and enzyme loading. More than $40 \mathrm{~g} \cdot \mathrm{L}^{-1}$ glucose was obtained from both pretreated materials at $13.7 \% \mathrm{w} \cdot \mathrm{w}^{-1}$ TS and $20 \mathrm{FPU} \cdot \mathrm{g}^{-1}$ glucan after $96 \mathrm{~h}$ of hydrolysis. Ionic liquid pretreatment of the same cotton spinning residues showed moderate delignification levels, accompanied by a change in biomass crystallinity from cellulose I $\beta$ to cellulose II. This turned to be very important to improve enzymatic hydrolysis yields. Therefore, biomass delignification and crystallinity confirmed to be key factors governing the enzymatic saccharification of cotton spinning residues.
\end{abstract}

() 2019 Elsevier Ltd. All rights reserved.

\section{Introduction}

In the last few decades, agro-industrial residues have been considered interesting and promising feedstocks for the production of energy, fuels, chemicals and materials [1]. To accomplish this target, advanced biomass pretreatment techniques are needed $[2,3]$. Currently, several types of pretreatments have already been proposed including chemical, physical, biological and a combination of these. In general, all of them have the same objective, i.e. a reduction of the enzyme loading needed to achieve a satisfactory release of upgradable sugars by enzymatic hydrolysis [2]. This, in turn, can be achieved by removing lignin, increasing biomass surface area, or introducing changes in biomass crystallinity. Lignin

\footnotetext{
* Corresponding author.

** Corresponding author.

E-mail addresses: luiz.ramos@ufpr.br (L.P. Ramos), rafal.lukasik@lneg.pt (R.M. Łukasik).
}

removal is often considered as one of the most important factors affecting enzymatic hydrolysis because lignin causes the unproductive and/or irreversible binding of cellulases and $\beta$-glucosidases [4].

An increase in biomass surface area has also a positive effect on enzymatic hydrolysis because it enhances the accessibility of enzymes to the processed solids [5]. Another important aspect is the biomass crystallinity. Cellulose $\mathrm{I}_{\beta}$ (monoclinic) is the most common and resilient allomorphic form of the cellulose component of vascular plants [6]. Its change to either cellulose II via ionic liquid processing $[7,8]$ or into cellulose $\mathrm{III}_{\mathrm{I}}$ through treatment with amines or ammonia are efficient methods to improve enzymatic hydrolysis without losing the polysaccharides during fractionation [9-11]. Nevertheless, the influence of each of these aforementioned factors on enzymatic hydrolysis is strongly dependent on the biomass type and its presentation and chemical composition.

Considering a large diversity of biomasses used worldwide, cotton is one of the most ancient and resistant to biological 